Please do not remove this page

RMIT

UNIVERSITY

\title{
Preparing new librarians for career and organizational impact
}

Leong, Julia; Vaughan, Maree

https://researchrepository.rmit.edu.au/esploro/outputs/9921857627701341/filesAndLinks?institution=61RMIT_INST\&index=null

Leong, J., \& Vaughan, M. (2010). Preparing new librarians for career and organizational impact. Library Management, 31(8/9), 635-644. https://doi.org/10.1108/01435121011093405

Published Version: https://doi.org/10.1108/01435121011093405

Repository homepage: https://researchrepository.rmit.edu.au

(c) Emerald Group Publishing Limited

Downloaded On 2023/04/26 20:31:19 +1000

Please do not remove this page 


\section{Preparing new librarians for career and organizational impact}

\section{Abstract \\ Purpose}

This case study reports on the activities and outcomes of a facilitated group of new librarians in one Australian university. Aims were to increase professional networking, to promote career development, to enhance job satisfaction and retention of motivated staff, to grow participants' sense of responsibility for organizational progress, and to develop willingness to take initiative in presenting good ideas for service improvement.

\section{Design/methodologylapproach}

The primary author was the initiator of, and facilitator for, the new professionals' group and was able to influence approaches taken. A variety of learning experiences was utilized including an action learning project. Monthly meetings were held face-to-face and an online group was used as an additional communication avenue. The progress of the group was monitored by facilitator observation, by a participant survey after several months of operation, and by feedback and analysis after one year.

\section{Findings}

Participation in the New Professionals' Group had positive impact on networking activity, career advancement, contribution to the organization and job satisfaction. No significant impact on staff retention was established.

\section{Research limitations/implications}

Self report was the only means of identifying the level of influence coming from participation in the group as compared with the impact of prior capabilities and attitudes.

\section{Originality/value}

Induction and socialization of new employees commonly covers organizational structure, policies and procedures as well as job-specific training. An emphasis on career advancement strategies and being a positive and effective voice for organizational improvement are distinctive in the reported work.

\section{Keywords \\ Librarians \\ Employee development \\ Australia}

\section{Paper type \\ Case study}

\section{Introduction}

This article reports on work undertaken at the RMIT University Library in Melbourne to assist new librarians in their career development and to prepare them to make positive contributions to their organizations. RMIT University is a large institution situated in Melbourne, Australia and in Ho Chi Minh City and Hanoi in Vietnam. It is a dual sector institution offering both tertiary and vocational and trade qualifications. As there are a number of campuses in Melbourne, the University Library has six libraries in that city.

Australian universities, like many of their international counterparts, are situated in a rapidly changing environment which is socially, politically, technologically and financially challenging. Although this has been the case for many years, policy changes announced by the Rudd Labor Government in 2009 have focussed attention on the need for greater competitiveness as student intake will be driven by student demand from 2012, rather than by the previous system of allocation of places by the Australian Government after negotiation with universities. There is also a push for higher participation rates across 
the community and particularly among lower socio-economic groups and those with an indigenous background. University libraries will need to respond by providing innovative support to the increasingly diverse and larger student populations. The capacity of libraries to respond to such changes lies in significant part in their organizational culture. As part of continuous improvement efforts to ensure Library services meet client needs, in 2008 twenty leaders in the RMIT University Library in Melbourne examined the current organizational culture of the Library, the desired culture, and how to progress towards this ideal. Some characteristics of organizational culture which were identified as desirable were: professionally engaged staff who are aware of current developments and engage in reflective practice; workforce flexibility; a continuous improvement and performance culture; role clarity; decisionmaking at appropriate levels with more decisions made at lower levels than was the case at that time; authority combined with an acceptance of responsibility; and a greater flow of ideas 'up-line' combined with an increased level of managerial responsiveness to new suggestions. The executives at the Library were conscious of a need to enhance levels of innovation and of acceptance of responsibility by staff throughout the Library. A number of strategies were implemented to progress towards the ideal culture which had been identified, including extensive leadership development, work planning training for supervisors and staff, and the formation of a New Professionals' Group.

Milliken and Lam (2009, p. 227) assert that 'facilitating employee voice' may be essential for 'organizational learning and adaption' to occur. One approach to 'facilitating employee voice' within the organization was work planning training for both supervisors and individual staff members, at which the value of feedback and encouraging suggestions for improvement from all levels of staff was emphasised. Another approach taken was to form a New Professionals' Group within the Library. It was hoped that early career professionals could be encouraged to be more proactive in seeking organizational excellence than might occur should they see themselves as 'junior newcomers' and should they conform to the prevailing culture which was characterised by some cynicism regarding the value of speaking up and an attitude that managers were solely responsible for decision-making.

\section{Methodology}

This case study reports on the formation, activities and outcomes of the facilitated group of new professionals at the RMIT University Library. The primary author was the initiator and facilitator of the group and was able to influence approaches taken. The secondary author was a group member who set up and managed an online forum for participants. A variety of learning experiences was utilised including face to face meetings, online forum postings, and an action learning project. The progress of the group was monitored by observation, by a participant survey after several months, and by survey/interview after one year.

\section{Literature pertaining to new professionals}

Oud (2008) provides useful insight into the needs of new academic librarians as they adjust to the workplace in an article in which she points to a lack of research on the topic, particularly in library literature. Her study is based on a survey of new librarians at Canadian university libraries and identifies a difference between pre-existing expectations and experience in their first job. Transition difficulties resulted in lower levels of job satisfaction. Oud states that most new academic librarians would benefit from help in adjusting to the workplace and found that the majority of areas of greatest discrepancy between expectation and actuality, and areas where a low level of knowledge was an issue, are related to organizational culture and politics, the unwritten rules of how things are done, and of when and how to take initiative.

The employer view of workforce needs and new professionals in the UK was analysed in a 1998 study (Goulding et al. 1999). The quality seen as most lacking was 'commitment to organizational goals'. The next qualities which were most often absent were friendliness, ability to accept pressure, reliability, and energy. In addition to the issue of 'commitment to organizational goals', of particular relevance to this study was 'innovative' which ranked at 17 out of 24 in the list of lacking qualities. Interestingly, Russell (2009) reported that 'professional development' and 'openness to innovation and change' are among the top things sought by new professionals who responded to a survey advertised on the Australian Library 
and Information Association (ALIA) New Grads email list regarding what people looked for in a job or library company.

The topic of staff development in the library and information services (LIS) workforce in Australia is part of the focus of the neXus2 project. Hallam (2009) reports that responding libraries see a clear need for ongoing training for new graduate staff, but that $20 \%$ reported 'less than half of the new graduates employed at their institution would actually attend training each year'. RMIT University Library offers a thorough induction process and ongoing skills training for new staff. The formation of the New Professionals' Group was intended to provide broader support and a degree of organizational socialization and savvy. Shaughnessy (1993) offers an analysis of methods to improve librarians' performance and effectiveness which is pertinent. He distinguishes between training and professional development and discusses the issue of providing professional development opportunities which promote attitudinal change and result in staff contributing to a more effective organization. Shaughnessy is interested in promoting risk-taking, the ability to function with high levels of ambiguity and change, a strong service-orientation, awareness of the political context, a deep understanding of 'the nature of information and its importance to the university community', and good analytical skills. He mooted that one approach to using professional development as a strategy for organizational change could be to begin with a small group of librarians who might become agents of change over time (Shaughnessy 1993, p. 292). A structured internship was seen as a way to achieve this. At RMIT University, the New Professionals' Group was established with strikingly similar intentions.

\section{The RMIT University New Professionals' Group}

\subsection{Formation and aims}

The New Professionals' Group first met in November 2008. Participation was invited from librarians or library technicians who had graduated in the previous five years and those currently studying for a LIS qualification. This was consistent with the mission statement of the International Federation of Library Associations New Professionals Special Interest Group which says the IFLA group represents 'a new generation of LIS students and recently qualified professionals' (IFLA 2010). The balance of participation from the different library sites would have been taken into account if all interested staff could not be accommodated, but this did not apply. The preferred group size was eight to ten and the final number of interested staff was ten. This number quickly dropped to eight as workloads and/or rostered work days made attendance impractical for two part-time staff.

The aims of the group were stated as follows -

1. Provide an opportunity for staff to support each other in developing their professional capabilities and in identifying and developing good ideas.

2. Develop capacity of staff to effectively take responsibility for promoting and implementing good ideas.

3. Help to develop promotion ready staff and potential leaders.

4. Enhance job satisfaction and retention of new professionals.

Expected benefits were -

1. Increased flow of good ideas.

2. Increased capability of staff to present suggestions in a well reasoned and clear manner.

3. Development of leaders.

4. Increased morale amongst participants.

The ALIA New Graduates Group (Australian Library and Information Association 2009) promotes networking, discussion of issues, meetings and training, and the IFLA New Professionals Special Interest Group (IFLA 2010) provides a discussion forum and networking opportunities, and is concerned with leadership development. The RMIT University group had similar intent, but its aims were focussed more specifically on organizational needs than would be appropriate for national or international groups. At times the breadth of aims appeared to generate some tension with individual preferences for group 
activities not always in tune with the direction taken. A few participants would have preferred a greater focus on career-building topics and fewer structured sessions.

\subsection{Topics of discussion}

Topics addressed related both to the organizational aims and those clearly of high interest to the new professionals. Initial emphasis was placed on organizational aspects - managing up, problem solving and preparing solutions - and these may have been better placed later in the life of the group.

\section{Adjusting to a new workplace}

The preparatory work for the first meeting was to read the article by Oud (2008) on adjusting to the workplace and to make notes regarding where their experience at RMIT University had varied from their expectations. Participants had found the Library staff very friendly, but had been surprised at how hierarchical the workplace was and expressed concern at what they described as 'silos' within the Library. This experience is consistent with Oud's findings that the greatest areas of discrepancy between expectations and reality relate to organizational culture and politics. Simmons-Welburn and Welburn (2003) warned that unmet or unrealistic expectations result in new employees leaving 'prematurely'. They stress the value in helping new employees 'make sense' of the organization. This first discussion topic, and others such as 'managing up' and 'influencing', were intended to achieve this 'sense-making', but also to encourage constructive action to improve the organization. It was at this first meeting that a decision was taken to tackle the question of 'silos' as an action learning project.

\section{Managing up}

The topic of 'managing up' generated lively discussion and proved to be of practical application and value. Personal experience suggests that it is quite uncommon for a supervisor to clearly define their expectations of direct reports and, as a consequence, satisfaction with the supervisory/subordinate relationship can suffer. Group members prepared for the meeting by asking their supervisor for five to six dot points on what they expect from people they supervise, for example 'take initiative' or 'offer solutions not problems'. There were also articles on managing-up tagged at http://delicious.com/julia.leong/managing-up for perusal and a section of a rather old, but relevant video (Gabarro \& Kotter 1986) was shown in the session.

\section{Problem solving}

In the UK study of the workplace needs of library and information services, Goulding et al (1999, p. 218) found a general consensus that innovativeness meant creativity and problem-solving ability. The respondents to the study believed that the ability to problem-solve and think critically and rationally was lacking in new graduates. At RMIT University, the New Professionals' Group facilitator had envisaged taking a relatively small problem and utilising a simple problem solving approach to encourage staff to include possible and recommended solutions when raising problems with supervisors. The group, however, decided to tackle the challenging issue of organizational 'silos' which was of concern to them. Initially two group members, with tuition from a Library Manager, led a session to define the problem using the Nominal Group Technique. As this coincided with the busiest time in the academic calendar, work on several aspects of the problem was progressed by pairs who worked either face to face or by email and then reported on ideas on the online forum. The Group generated excellent work which was used by leaders of a Cross Unit Coordination Project which was established while this topic was under discussion. However the action learning approach met with mixed reactions from participants. Some rated it very highly and others felt it was too formal, not appropriately meeting their needs. The Nominal Group Technique session was more popular than the work in pairs and was a good example of group members taking a leadership role. Despite the varied reactions to the action learning project, comments at the mid-year evaluation attested to a positive impact as a number mentioned they were more aware of the need to think systematically about problems. 
After the 'silos' project, the sessions were less structured. The University Librarian attended this multitopic meeting and addressed how he goes about working with other units in the University to enhance Library services. Although group members were less outgoing in the presence of the University Librarian, the session was highly rated. At this meeting, topics were identified for the following meetings and participants suggested particular Library managers they would like to invite to speak, partly with a view to getting to know them and gaining an insight into their viewpoints.

\section{Preparing for higher duties}

After six months in operation, participants expressed concern about being exclusive and the group was opened up to new members. Around this time some of the original group members ceased attending regularly. The next "open" session was an informal talk by a Library manager on his career choices and how he took a proactive approach to seek opportunities to broaden his experience and to obtain promotion.

\section{Assertiveness at work}

Goulding et al. (1999, p. 221) affirmed that assertiveness training is of worth to help new professionals to be confident when dealing with management, colleagues and users. The topic was covered by a panel of three Library managers who included personal examples of where assertiveness had been important and how they had handled these situations. Two of the topics covered were assertiveness in meetings and how to maintain assertiveness when faced with opposition. To give a flavour of the frank and practical nature of the discussion, here are some of the specific tips which were made regarding assertiveness in meetings - know your material before you attend; arrive early, 'mingle' with people before the meeting starts; canvass people beforehand and know where they stand; speak up with your ideas; be aware that you can add to the discussion after the meeting ends, via email or in person; fall back on the chairperson and use them if things are going off the rails; do not be disappointed if your ideas do not get a lot of attention at first; make sure you put things you want raised on the agenda; if bringing a new item to the meeting, consider lobbying beforehand, predict opposing views, practise your delivery, talk to the Chair about the fact that you are going to canvass the issue, and distribute supporting documents prior to the meeting.

\section{Tours}

As most of the participants worked in information services, a morning tea to meet colleagues and a tour were arranged with the technical services area of the Library. The final two meetings were tours of the National Gallery of Victoria Library and the AFI (Australian Film Institute) Research Collection. These visits gave good insight into the different demands of working in small special libraries.

\subsection{Learning approaches}

In order to cater for different learning styles, a variety of approaches was utilised. Examples are preparatory reading, interviewing a supervisor, watching a video, listening to informal talks from experienced librarians, a panel discussion by managers, tours of other libraries, an action learning project, and discussions. Participants reported high levels of completion of preparatory work for sessions. A number of participants preferred informal discussions rather than structured sessions. Face to face learning experiences were supplemented by use of the online forum which was well, although not heavily, used. Preparatory work for meetings was posted there as were summary ideas from each meeting and this ensured those who could not attend a meeting were able to keep up to date. People introduced themselves on the forum and there were useful discussions and postings including reports on sessions attended at the 4th ALIA New Librarians Symposium (2008, Melbourne). It should be noted that interested supervisors of participants and the University Librarian also joined the online forum. This may have reduced informal discussion, but it was intended to integrate the learning experience with the 
workplace. As the University Librarian responded to some posts, people were aware of his interest and appreciated it.

From the facilitator's viewpoint, the action learning project was important as it reinforced the value of positive outcomes for the organization. It was also a key learning experience as it put participants into a more 'real' work situation. It resulted in quite fascinating group dynamics, well-meant interpersonal misunderstandings, and heightened levels of 'corridor' talk as individuals voiced opinions away from the whole group. In retrospect, it would have been judicious to spend time together looking at how groups work and seeking open communication regarding what roles each individual felt comfortable filling in a group context. It may also have been useful for the group to be allocated a real project. The action learning project was around a real need and turned out to be useful and used, but it was not a given that this would be the case at the outset, and at least one participant was uncomfortable with what they felt was a 'contrived' learning experience.

\subsection{Outcomes}

The aims in establishing the group were broad and ambitious. The full impact will not be seen for some years and it will not be possible to make clear links to this learning initiative. Despite this reservation, there are clear and positive outcomes which match the original aims.

The first listed aim included providing 'an opportunity for staff to assist each other in developing their professional capabilities'. The opportunity to network was appreciated by participants who made comments at the final survey/interview such as:

- It reduced my feeling of isolation.

- $\quad$ [t] helped me think about my career more closely.

- Attending the group tapped me into Staff Development opportunities.

- Attending the group sharpened my thoughts, gave me time to reflect, gave me access to people in higher level positions, plus I learned a lot about my Supervisor while doing the homework for the 'Managing up' session.

Staff members benefited from knowing whom to contact at other sites and shared information on different Library Studies courses. One participant credits membership of the group with influencing her to consider her career options which led her to take a one-year post in a school in Vanuatu through Australian Volunteers International. In response to encouragement to present conference papers, Giddens and Phillips (2009) collaborated on a presentation to the ALIA National Library and Information Technicians Conference and, as is self-evident, another group member collaborated with the facilitator on this paper. Participation in the professional association, ALIA, was promoted in the group, but this was probably unnecessary as most were already ALIA members. The New Librarians Symposium was also discussed in a group meeting and this did result in at least two additional conference attendees.

Another aim was to 'develop capacity' to 'take responsibility for promoting and implementing good ideas'. Not all reported a change in their behaviour in this area, but awareness of problem solving techniques was raised. The action learning project did result in a number of good ideas being put to a Library-wide project which was formed later to improve cross unit cooperation. The project leaders affirmed that the content of the New Professionals' deliberations and documentation was invaluable in 'getting started' and had 'quite an impact' on their thinking.

The third aim was to 'help to develop promotion-ready staff and potential leaders'. Outcomes have been excellent. Almost every participant has taken steps to gain varied work experience or promotion in the year of group operation. This is a group of highly motivated individuals and it would be fallacious to claim that group involvement was instrumental in all of these moves, but at least half see their group involvement as a catalyst. Several took either full time or part time secondments to other RMIT Library sites, and one took a one year secondment to another university to build skills in an area of career interest. As mentioned previously, one worked overseas. One volunteered for a Library-wide project, one has acted at a higher level for several months, and two have obtained continuing promotions. 
The impact on job satisfaction was varied with a number saying it had 'some' or 'strong' positive impact and others saying 'no impact'. Impact on staff retention was not particularly significant according to selfreport at the final survey, but no members of the group resigned from the employ of RMIT University in the time period concerned.

\section{Lessons learned}

Leadership of the group was dominated by the facilitator who was unsuccessful in transiting leadership effectively to group members in any sustained way. This was a source of disappointment to both the facilitator and group participants. As librarianship is popular as a second career, ages of group members and levels of work experience in other fields varied. More experienced workers privately expressed a desire not to dominate and thus held back from exercising leadership, but there was no evidence forthcoming from the lesser experienced workers to suggest that they were sensitive to this issue. An approach to increasing participant leadership within the group would be to have the group nominate a leadership pair or trio to liaise with the facilitator who would not then need to attend all meetings.

An article by Sessa and London (2008) may offer insights to formulate other improvements for future groups, although the context is different as their article is about promoting learning in groups which are formed for a work task or tasks, whereas in the New Professionals' Group learning was the primary task with a 'work' task included as an action learning project. Sessa and London identify three major characteristics of groups that influence learning readiness. These are 'maturity, boundary permeability, and learning orientation'. Regarding group maturity they state:

Group maturity is the process of moving from a simple collection of individuals towards a complex and integrated system. In an immature, un-integrated group, individuals retain separate views, work on their own, are often not committed to the group as a whole, and learn on their own. In a fully integrated and mature group, the group works, learns, and makes decisions as a single unit.

They go on to say that progress to becoming a holistic system requires 'mutual trust, a shared mental model, a group identity, cohesiveness, and potency'. While these were developed in the New Professionals' Group, it would have been beneficial to pay more attention to their development. In particular, more time was needed to develop a 'shared mental model' regarding the purpose of the group and the way each could contribute to working together. Also higher levels of mutual understanding, respect and trust may have been formed earlier if the first sessions had been less structured. The action learning project could then have taken place once the group had reached maturity. In future it is planned to seek a small scale Library project for group members to work on together in a less busy period of the academic year. As this would be a 'real' rather than 'contrived' project it would be likely to appeal to a wider number of group members and generate sustained effort.

Proposed improvements for future groups are:

- Use an informal discussion-based approach to early meetings and allow time for participants to get to know each other and to bond.

- Include input on group stages and the roles individuals may play in a group.

- Implement deliberate strategies to develop leadership within the group.

- Provide a real group project for participants to work on with Library-wide approval.

\section{Practical implications}

The approach to staff development reported in this case study is low cost and was found to be effective. It can be flexibly adjusted to group and organizational needs. With greater resources each topic could be more thoroughly researched or professional facilitators could be involved. This would not necessarily improve outcomes though as the participants enjoyed free flowing discussions. In this instance the program ran for a set time period of 12 months, but this could be extended or decreased. The major impact was felt in six months so the time allowed could be less than 12 months. To be successful requires a competent facilitator, enthusiastic participants and support from supervisors. Where an 
organization has insufficient new graduates to form a group, working jointly with another organization is a practical solution.

\section{References}

Australian Library and Information Association. (2009), "ALIA New Graduates Group", available at: http://alia.org.au/groups/newgrad (accessed 14 February 2010).

Gabarro, J.J. and Kotter, J.P. (1986), Managing Your Boss, Harvard Business Review video series, WGBH Education Foundation.

Giddens, D. and Phillips, R. (2009), "Reverse mentoring: Finding a new way of working while discovering Web 2.0", paper presented at ALIA National Library and Information Technicians Conference, 1518 September, Adelaide Convention Centre, available at: http://conferences.alia.org.au/libtec2009/Documents\%20for\%20Links/Giddens-PhillipsALIA09.pdf (accessed 23 November 2009).

Goulding, A., Bromham, B., Hannabuss, S. and Cramer, D. (1999), "Supply and demand: The workforce needs of library and information services and personal qualities of new professionals", Journal of Librarianship and Information Science, Vol. 31, pp. 212-23.

Hallam, G. (2009), "The strategic and operational dimensions of staff training and professional development for informational professionals: What neXus2 has revealed", paper presented at Information Online 2009: ALIA 14th Exhibition \& Conference, 20-22 January 2009, Sydney Convention \& Exhibition Centre, available at: http://www.informationonline.com.au/sb_clients/iog/data/content_item_files/000001/PresentationC20.pdf (accessed 23 November 2009).

IFLA. (2010), "About the New Professionals Special Interest Group: mission," available at: http://www.ifla.org/about-new-professionals (accessed 27 April 2010).

Milliken, F.J. and Lam, N. (2009), "Making the decision to speak up or to remain silent: Implications for organisational learning", in Greenberg, J. and Edwards, M.S. (eds), Voice and Silence in Organizations, Emerald, Bingley, pp. 225-44.

Oud, J. (2008), "Adjusting to the workplace: Transitions faced by new academic librarians", College \& Research Libraries, Vol. 69, No. 3, pp. 252-66.

Russell, F. (2009), "On the flip side: Career motivations and aspirations of new professionals in the information industry", paper presented at People in the Information Professions, 15-16 October 2009, Victoria University, Melbourne, available at:

http://www.caval.edu.au/assets/files/CHRG/People_Conference/Session_D_Room_2/Fiona_Rus sell_Updated_new_prof_career_09.pdf (accessed 18 November 2009).

Sessa, V.I. and London, M. (2008), "Interventions to stimulate group learning in organizations", Journal of Management Development, Vol. 27, No. 6, pp. 554-73.

Shaughnessy, T.W. (1993), "Approaches to developing competencies in research libraries", Library Trends, Vol. 41, No. 2, pp. 282-98.

Simmons-Welburn, J. and Welburn, W.C. (2003), "Organizational entry, sense making and new professional employees in academic libraries", paper presented at ACRL Eleventh National Conference, April 10-13, Charlotte, North Carolina, available at: http://www.librarycareers.org/ala/mgrps/divs/acrl/events/pdf/simmons-welburn.PDF (accessed 23 November 2009). 